\title{
Gender differences in subliminal affective face priming: A high-density ERP study
}

\section{Mutsuhide Tanaka ( $\nabla$ mtanaka@phoenix.ac.jp)}

Kyushu Daigaku Igakubu Daigakuin Igakukei Gakufu Daigakuin Igaku Kenkyuin https://orcid.org/0000-0003-4143-0819

\section{Emi Yamada}

Kyushu Daigaku Igakubu Daigakuin Igakukei Gakufu Daigakuin Igaku Kenkyuin

\section{Toshihiko Maekawa}

Kyushu Daigaku Igakubu Daigakuin Igakukei Gakufu Daigakuin Igaku Kenkyuin

\section{Katsuya Ogata}

Kyushu Daigaku Igakubu Daigakuin Igakukei Gakufu Daigakuin Igaku Kenkyuin

Naomi Takamiya

Kyushu Daigaku Igakubu Daigakuin Igakukei Gakufu Daigakuin Igaku Kenkyuin

Hisato Nakazono

Kyushu Daigaku Igakubu Daigakuin Igakukei Gakufu Daigakuin Igaku Kenkyuin

Shozo Tobimatsu

Kyushu Daigaku Igakubu Daigakuin Igakukei Gakufu Daigakuin Igaku Kenkyuin

\section{Research article}

Keywords: Subliminal affective priming effects, Fearful face perception, N170, Gender difference

Posted Date: November 18th, 2019

DOI: https://doi.org/10.21203/rs.2.17380/v1

License: (c) (i) This work is licensed under a Creative Commons Attribution 4.0 International License. Read Full License

Version of Record: A version of this preprint was published at Brain and Behavior on February 2nd, 2021. See the published version at https://doi.org/10.1002/brb3.2060. 


\section{Abstract}

Background Subliminal affective priming effects (SAPEs) refer to the phenomenon by which the presentation of an affective prime stimulus influences the subsequent affective evaluation of a target stimulus. Previous studies have shown that behavioural performance is affected more by unconsciously processed stimuli than by consciously processed stimuli. However, the impact of SAPEs on the face-specific N170 component is unclear. In the current study, we investigated how subliminal processing of fearful faces affected the N170 for subsequent supraliminal target faces using event-related potentials (ERPs).

Methods We used event-related potentials (ERPs) to study how SAEPs for fearful faces affect the N170 for subsequent supraliminal target faces. Japanese adults ( $n=51,24$ females) participated in this study. Subliminal prime faces (neutral or fearful) were presented for $17 \mathrm{~ms}$, followed by a backward mask for $283 \mathrm{~ms}$ and target faces for $800 \mathrm{~ms}$ (neutral, emotionally ambiguous-fearful, or fearful). ERPs (128-ch) were recorded while participants judged the expression of target faces as neutral or fearful.

Results Behavioral data revealed that participants judged target faces as more fearful in the fearful face prime condition compared with the neutral prime condition, regardless of emotional expression. Interestingly, we found gender-related differences in N170 amplitude; only female participants exhibited enhanced N170 amplitude for neutral faces primed by fearful faces. Therefore, a noticeable gender difference exists in the neural processing of subliminally perceived facial emotions.

Conclusions Our ERP results suggest the existence of a gender difference in target-face processing preceded by subliminally presented face stimuli in the right occipito-temporal regions.

\section{Background}

Facial information conveys the emotional status of others, making it possible to infer others' intentions and appropriately alter subsequent social cognition and behaviour. Previous studies have suggested that specific neural substrates in the extrastriate cortex are involved in face processing [1-5]. The inferior occipital gyrus (occipital face area, OFA) is thought to be involved in the initial processing and encoding of face parts [6], while the fusiform face area (FFA) mediates the analysis of holistic face structure [7], and the superior temporal sulcus (STS) is involved in the analysis of eye gaze, facial expression, and identity [8]. Electrophysiological studies using event-related potentials (ERPs) have indicated that early face processing occurs approximately 100-200 ms post-stimulus onset, reflected by the P1 [9] and N170 ERP components inoccipito-temporal regions $[1,2,10]$. N170 is reported to function as a face specific component, exhibiting maximal negative peak amplitude over the right occipito-temporal regions, possibly corresponding to the FFA or STS [11,12]. Accumulating evidence has also suggested that N170 is sensitive to emotional expression [13-15]. Thus, the early processing represented by N170 is thought to be responsible for the detailed face processing that underlies the differentiation of basic emotions.

The social significance of emotional information is often assumed to be processed automatically. Although most studies define happiness, sadness, anger, disgust, surprise, and fear as basic emotions, whether a set of basic emotions actually exists remains controversial [16]. However, based on the evolutionary viewpoint, stimuli that indicate an imminent threat, such as fearful facial expressions, should be rapidly processed in order to evoke extremely rapid social reactions [17]. For instance, activity in the amygdala is known to reflect various categories of emotion such that responses to fearful faces or bodily expressions are especially rapid and more intense when subjects unattended or unconsciously perceived fearful stimulus [18-21]. Lesion studies have demonstrated that unconsciously perceived fearful face stimuli produce an amygdala response in the damaged hemifield, including the right fusiform cortex [22,23]. Similarly, our previous study[24] reported that subliminally presented face stimuli elicited an occipital P1 (approximately $120 \mathrm{~ms}$ ) component, and also demonstrated a trend towards larger P1 amplitude in the subliminal fearful face condition. Several studies have claimed 
that such unconscious fear processing depends on a subcortical route that typically bypasses the visual cortex. Instead, the amygdala receives threat-related visual information via the superior colliculus and pulvinar thalamus $[19,21,25]$. Thus, the subcortical pathway to the amygdala, probably including a magnocellular channel, is thought to be specialized for processing the low spatial frequency information of fearful images [26]. With this type of subcortical route, such information would be perceived without consciousness. Together, these findings suggest that unconsciously perceived affective (particularly threat-predicting) information may modulate the amygdala-visual cortex network by regulating subsequent volitional behaviour.

Amygdala modulation of occipital regions is thought to underlie subliminal affective priming, the phenomenon by which subliminal presentations of affective prime stimuli shift subsequent affective evaluation of supraliminal target stimuli $[27,28]$. Such affective evaluation suggests the existence of a fast-acting affective information-processing system, in accord with the finding that people are able to form a preference among several items before they are able to explain the reasons for that preference $[27,28]$. Recent neurophysiological and neuroimaging studies have used the backward masking paradigm to reveal the neural substrates underlying the processing of subliminal affective objects. Several ERP studies have suggested that ERP components, such as N2/P3 recorded from a midline site, are enhanced more by subliminally presented fearful faces than by supraliminally presented fearful faces [14,29-33]. Furthermore, Pegna et al. [34] reported that subliminally presented fearful faces elicited larger N170 amplitudes than did supraliminally presentation of fearful faces. These findings indicate a double dissociation for subliminal versus supraliminal processing of fearful faces [32], raising the possibility that subliminally presented fearful face stimuli may affect the perception of subsequently presented supraliminal face stimuli via subcortical visual pathways. However, subliminal affective priming effects (SAPEs) on subsequent supraliminally presented target-face stimuli remain unclear because of the superimposition of ERP responses for the prime and target faces. In previous behavioural studies, affective priming effects have been obtained with a relatively short (300 ms) prime-target interval (stimulus onset asynchrony; SOA) [35]. Therefore, the current study sought to investigate neural activity accompanying SAPEs using high-density electroencephalogram (EEG) with the subliminal priming paradigm adapted from Fazio et al. [35]. We hypothesized that subliminally presented fearful face stimuli would negatively shift the subsequent emotional judgment of the target face. Accordingly, we predicted that face-related ERP components (P1, N170, P2) would be more prominent in the fearful face priming condition than in the neutral priming condition. Interestingly, previous behavioural evidence has suggested a gender difference in affective priming, with female participants tending to respond to positive affective information and male participants exhibiting strong priming effects in emotionally negative conditions [36,37]. Therefore, we predicted that the results would reveal gender-related ERP differences in SAPEs for fearful faces.

\section{Methods}

\section{Participants}

Fifty-one healthy Japanese adults (20-32 years old; mean age: $23.1 \pm 3.1$ years; 24 females) participated in this study. All participants were right-handed and all had normal or corrected-to-normal vision. None had a history of neurological or psychiatric disorders. All participants provided written informed consent. The experimental procedure was approved by the Ethics Committee at the Graduate School of Medical Science, Kyushu University (24078), and methods were carried out in accordance with the relevant guidelines. This research was conducted in accordance with the Helsinki Declaration as revised 1989.

\section{Visual stimuli}

Prime-face stimuli consisted of grayscale photographs of four Japanese actors (two males and two females) exhibiting fearful or neutral expressions, resulting in a total of eight different prime-face stimuli. Target-face stimuli included fearful, 
ambiguous-fearful, and neutral expressions displayed by four Japanese actors (two males and two females), who were not the actors used for the prime-face stimuli. We used Morpher 3.1 freeware to generate a series of target-face stimuli with ambiguous-fearful emotional facial expressions. Ambiguous-fearful stimuli were created by morphing together faces with fearful and neutral expressions. We generated three types of ambiguous-face stimuli that differed in their fearful to neutral face ratios (25\%,50\%, and $75 \%$ fearful faces). Thus, a total of 12 different facial stimuli were included in the ambiguousfearful subset of target-face stimuli (i.e., 3 graded intensity levels $\times 4$ identities, see Fig. 1A). The original facial images were taken from the ATR face database (ATR Promotions, Inc., Kyoto, Japan) (for detailed descriptions of the face database, see section Supplementary Information SI.1). All face stimuli were converted to grayscale and cropped into an oval shape to exclude all hair and non-facial contours. Scrambled mask stimuli were generated using a MATLAB R2013a (The MathWorks Inc., Natick, MA, USA) script. All images were equated for luminance $\left(15 \mathrm{~cd} / \mathrm{m}^{2}\right)$ and contrast ( $\left.80 \%\right)$. All stimuli were presented on a 19-inch CRT monitor (refresh rate: $60 \mathrm{~Hz}$ ) at a viewing distance of $114 \mathrm{~cm}$, and subtended a visual angle of $5.3^{\circ} \times 8^{\circ}(283 \times 413$ pixels) (See Fig. 1A).

\section{Rating of ambiguous-fearful target-face stimuli}

Participants sat in a dimly lit, sound-attenuated, and electrically shielded room. The experiment was programmed using Presentation software (version 16.3, Neurobehavioral Systems, 2016; http://www.neurobs.com/) to display the prime and target-face stimuli.

Before the experiment, we used the three morphed ambiguous-fearful face categories (25\% fearful, $50 \%$ fearful, and $75 \%$ fearful) (Fig. 1A) to determine the ambiguous-fearful target face for each participant. A face was defined as ambiguousfearful for a participant if they judged it to be fearful about $50 \%$ of the time (chance level). At the beginning of each test, a scrambled mask stimulus with a red fixation cross appeared in the middle of the screen for $1000 \mathrm{~ms}$. Following a scrambled mask, one of the test faces (neutral, one of three fearful morph levels, or fearful) was displayed on the screen for $1000 \mathrm{~ms}$ and then replaced by a scrambled mask. Each of the five face categories was presented 48 times in pseudorandom order. Participants were instructed to judge whether the target face was "neutral" or "fearful" by clicking the left or right mouse button with their right hands. Response buttons were counterbalanced across participants. We defined the ambiguous fearful target face category as stimuli for which the fearful response rate (RR) of each participant was approximately $50 \%$. After determining the ambiguous-fearful faces for each participant, the stimuli that were ambiguousfearful for all participants were used as the ambiguous-fearful face stimuli for the ERP experiment.

\section{Affective subliminal priming task}

We adopted the backward masking paradigm from Mitsudo et al. [24]. Each trial began with mask stimuli and a red fixation cross lasting $1000 \mathrm{~ms}$. A prime-face stimulus was displayed for $17 \mathrm{~ms}$, immediately followed by the mask stimulus for 283 ms (SOA was $300 \mathrm{~ms}$ ) and then a target-face stimulus for $800 \mathrm{~ms}$ (see Fig. 1B). Participants were instructed to judge whether the target face was fearful or neutral as quickly as possible by pressing the left or right mouse button with their right index finger. The response button assignment was counterbalanced across participants. After the experiments, participants were asked if they had noticed the prime faces. Because Mitsudo et al. [24] reported that threshold durations for subliminal stimuli ranged from 20 to $50 \mathrm{~ms}$, our choice of a 17-ms duration was sufficient for avoiding conscious perception of the prime stimuli.

Each prime-face stimulus subset (neutral or fearful) included four stimuli (two male actors and two female actors) and each target-face stimulus subset (neutral, ambiguous-fearful, or fearful) also comprised four identities. Six different trial types were formed from these prime and target pictures (i.e., neutral prime/neutral target, neutral prime/ambiguous-fearful target, neutral prime/fearful target, fearful prime/neutral target, fearful prime/ambiguous-fearful target, and fearful prime/fearful target). Each trial type was presented 144 times in a pseudorandom order. Thus, the total number of trials in 
the experiment was 864 ( 6 trial types $\times 144$ times). RRs and reaction times (RTs) were calculated from the behavioural data for each participant.

\section{ERP recordings}

ERP data were recorded while participants performed the affective subliminal priming task. Continuous ERPs were recorded using a high-density 128-channel system (NetAmps 200, Electrical Geodesics Inc., Eugene, OR, USA), and data were on-line bandpass filtered from 0.01 to $100 \mathrm{~Hz}$ and sampled at $1000 \mathrm{~Hz}$. ERP data were recorded continuously with the vertex electrode $(\mathrm{Cz})$ as a reference and offline re-referenced to the average reference. We processed ERP data offline using Net Station 4.2 software (Electrical Geodesics Inc., Eugene, OR, USA) with a 0.5-30 Hz bandpass filter, and segmented data from $100 \mathrm{~ms}$ before prime-face onset to $700 \mathrm{~ms}$ after target-face onset, corrected to a $100 \mathrm{~ms}$ pre-stimulus baseline. EEG epochs containing artefacts (EEG voltage exceeding $100 \mathrm{QV}$ or eye movements in excess of $55 \mathrm{\square V}$ ) were automatically rejected from further analysis.

\section{Data analysis}

We determined the time windows for ERP components based on butterfly plots and a microstate analysis [38]. First, we drew the butterfly plots by superimposing all 128 channels for all conditions and sought out salient ERP components by visual inspection (Fig. 2).

Next, we applied the microstate analysis to determine significant ERP components and their associated time windows. The aim of a microstate-segment analysis is to provide information about the brain activity associated with the sequence of discrete (and non-periodic) information-processing operations evoked by a stimulus or task [38]. Microstate segment analyses were carried out using Microstate Analysis Toolbox (MST) [39] from the EEGLAB toolbox[40]. All ERP data from the 6 conditions (male or female $\times 6$ stimuli) were added together and grand-averaged. Then, they were segmented into 3 and 20 microstate classes using a K-means algorithm with 50 random initializations for clustering. Finally, we selected microstates using three criteria; global explained variance (GEV), cross-validation (CV), and Krzanowski-Lai (K-L) criterion. In our data, the suitable number of segments for explaining the all epochs was 18. Accordingly, we fit the microstate prototypes back to all grand-averaged data. This procedure enabled us to label the EEG epochs with the microstate prototypes.

\section{Statistical analysis}

For SAPEs, RRs, and RTs were analysed with a $2 \times 3 \times 2$ repeated-measures analysis of variance (ANOVA) with prime-face category (neutral or fearful) and target-face category (neutral, ambiguous-fearful, or fearful) as within-participant factors, and gender (female or male) as the between-participant factor. ERP amplitudes and latencies were analysed using a $2 \times 3 \times$ 2 repeated-measures ANOVA with prime-face category (neutral or fearful), target-face category (neutral, ambiguous-fearful, or fearful), and laterality (left or right region of interests (ROI)) as within-participant factors. The results of the microstate analysis suggested significant gender-based differences in the time windows for each ERP component, especially N170. Thus, ANOVAs were performed separately by gender. All analyses were conducted with SPSS (version 22; IBM Corp, USA). All significant $p$-values were corrected by Greenhouse-Geisser correction, and Bonferroni correction was used for multiple comparisons.

Multiple regression analyses were also conducted to evaluate the correlation between behavioural and ERP results. We evaluated the correlation between within-participant factors (prime face and target face categories), behavioural data, and amplitudes and latencies of each ERP component. Thus, dummy variables were used to indicate intra-participant factors. Dummy variables for prime- and target-face categories were determined by the emotional intensity of the face categories

Page 5/26 
(prime face: neutral $=1$, fearful $=2$, target face: neutral face $=1$, ambiguous-fearful face $=2$, fearful face $=3$ ). Multiple regression analysis was performed separately for gender and laterality.

\section{Results}

\section{Behavioural results}

Data from five participants were discarded because they contained inappropriate behavioural responses (i.e., mean RR or mean RT for the target-face stimuli exceeded more than three times the inter-quartile range). Thus, the final analysis included data from 46 participants. After the experiment, all participants reported that they were completely unaware that prime-face stimuli had been used. Behavioural results indicated that mean RR for ambiguous-fearful target faces was $33.8 \% \pm 3.1 \%$.

Table 1 summarizes the results of the three-way ANOVA (prime $\times$ target $\times$ gender) for RRs and RTs. We found a significant main effect of Prime Face $\left(F(1,44)=4.456, p=0.041, \eta^{2}=0.09\right)$. RRs for the fearful prime condition were significantly higher than those for the neutral prime condition (fearful prime condition vs. neutral prime condition $=44.06 \pm 1.48 \%$ vs. $43.29 \pm 1.39 \%, p=0.032$ ) (Fig. 3A). We also observed a significant main effect of Target Face $(F(1.28,56.60)=762.79, p<$ $\left.0.001, \eta^{2}=0.95\right)$. Post hoc analysis revealed significantly higher RRs for fearful target-face stimuli than for neutral and ambiguous-fearful target-face stimuli (fearful target-face vs. neutral target-face $=90.55 \pm 1.16 \%$ vs. $4.35 \pm 0.60 \%, p<$ 0.001 , fearful target-face vs. ambiguous-fearful target-face $=90.55 \pm 1.16 \%$ vs. $33.77 \pm 3.04 \%, p<0.001$ ). RRs for ambiguous-fearful target-face stimuli were also significantly higher than those for neutral target-face stimuli (ambiguousfearful target-face vs. neutral target-face $=33.77 \pm 3.04 \%$ vs. $4.35 \pm 0.60 \%, p<0.001$ ) (Fig. 3B). We did not find any significant main effect of Gender or any significant interactions between Prime Face, Target Face, or Gender.

The three-way ANOVA (prime $\times$ target $\times$ gender) for RTs revealed a significant main effect of Target Face $(F(1.41,62.16)=$ $11.11, p<0.001, \eta^{2}=0.20$ ) (Table 1). Post hoc analysis revealed that RTs for the ambiguous-fearful target faces were significantly higher than those for neutral faces (ambiguous-fearful target-face vs. neutral target-face $=539.34 \pm 14.98 \mathrm{~ms}$ vs. $514.40 \pm 13.22 \mathrm{~ms}, p<0.001$ ) (Fig. 3C). No other main effects or interactions were significant.

\section{ERP results}

\section{Microstate analysis}

Figure 2 shows butterfly plots for each group. We found three major components within an approximately $400-550 \mathrm{~ms}$ time window (100-250 ms after target face onset) for male and female data sets. Interestingly, we observed temporal differences among these components between female and male groups. The microstate analysis (Fig. 4, Supplementary Information Fig. S1) revealed three microstates between 418-659 ms (118-359 ms after target face onset) for each prime $\times$ target condition. Microstate topography suggested that each microstate responded strongly among regions near the occipito-temporal electrodes. The first microstate overlapped between 418-447 (114-147) ms in females and between 419-447 (119-147) ms in males. The second microstate overlapped between 473-503 (173-203) ms in females and at 444-488 (144-188) ms in males. The third microstate overlapped between 511-545 (211-245) ms in females and between 515-559 (215-259) ms in males. We used these time windows to determine the conventional ERP components; P1, N170, and P2. Peak amplitudes and latencies for the ERP components were calculated at clusters of electrodes, corresponding to specific ROIs. ROIs for each component were defined as the electrode that recorded the maximum amplitude and its three spatially adjacent electrodes. P1 was measured around electrodes at 01 and 02. N170 was measured around electrodes at T5 and T6. P2 was measured around electrodes at T5 and T6 (for detailed descriptions of ROI definitions, see section SI.2, Supplementary Fig. S2).

Page 6/26 


\section{P1 component}

The results of the three-way ANOVA (prime $\times$ target $\times$ laterality) are shown in Table 2 . We found a significant main effect of Target Face on P1 amplitude (Males: $F(2,46)=8.31, p<0.001, \eta^{2}=0.27$, Females: $F(2,42)=8.79, p<0.001, \eta^{2}=0.30$ ), suggesting that P1 amplitude for fearful target faces is significantly greater than that for neutral and ambiguous fearful target faces in both genders (Male: fearful vs. neutral vs. ambiguous-fearful target face $=5.03 \pm 0.35 \mu \mathrm{V} v s .4 .80 \pm 0.33 \mu \mathrm{V}$ vs. $4.75 \pm 0.35 \mu \mathrm{V}, 0.001<p<0.023$, Female: fearful vs. neutral vs. ambiguous-fearful target face $=4.35 \pm 0.30 \mu \mathrm{V}$ vs. 4.06 $\pm 0.31 \mu \mathrm{V}$ vs. $4.09 \pm 0.308 \mu \mathrm{V}, 0.003<p<0.008)$. We also found a significant main effect of Laterality in males $(F(1,23)=$ 11.36, $p<0.001, \eta^{2}=0.33$ ), with P1 amplitude being significantly larger in the right occipital ROI than in the left ROI (Right vs. Left $=5.17 \pm 0.38 \mu \mathrm{V}$ vs. $4.54 \pm 0.34 \mu \mathrm{V}, p=0.003$ ) (for the time-course representation of the ERPs, see Supplementary Fig. S3).

A three-way ANOVA (prime $\times$ target $\times$ laterality) of P1 latencies revealed a significant main effect of Laterality in females $(F$ $\left.(1,21)=5.27, p=0.03, \eta^{2}=0.032\right)$ (Table 2) such that P1 latency in the right ROI was significantly shorter than in the left ROI (Right vs. Left $=424.48 \pm 1.18 \mathrm{~ms}$ vs. $426.0 \pm 1.34 \mathrm{~ms}, p=0.032$ ). We found no significant main effects for the prime conditions.

\section{N170 component}

Although no significant difference in prime conditions or target-face categories was evident in the grand averaged waveforms (or the time course representation of the ERPs, see Supplementary Fig. S3), a definite gender difference in SAPEs was found in the grand averaged waveforms and scalp topography in the right ROI (Fig. 5). Although visual inspection indicated that N170 amplitudes for neutral target-face stimuli were larger in the fearful prime condition than in the neutral prime condition for female participants, no such differences were evident for male participants (Fig. 5B, 5D). Three-way ANOVA (prime $\times$ target $\times$ laterality) calculated for N170 amplitude revealed significant interactions in each group (females: Prime Facex Target Face $\times$ Laterality $\left(F(2,42)=4.88, p=0.017, \eta^{2}=0.19\right)$; males: Prime Face $\times$ Laterality $(F(1$, $\left.23)=12.29, p=0.002, \eta^{2}=0.35\right)$ ) (Table 2). Further statistical analysis revealed gender differences in SAPEs. N170 amplitude for neutral target faces in the fearful prime-face condition was significantly larger than that in the neutral primeface condition, but only in the right $\mathrm{ROI}$ of the female participants $(-1.63 \pm 0.20 \mu \mathrm{V}$ vs. $-1.42 \pm 0.19 \mu \mathrm{V}, p=0.013)$ (Fig. 5B, $\mathrm{D}$ and $6 \mathrm{~B})$. In contrast, no significant SAPEs were found in the male participants. We only found that N170 amplitude in the right ROI during the fearful priming condition was significantly larger than that in the left ROI $(-2.98 \pm 0.32 \mu \mathrm{V} v s .-2.86 \pm$ $0.32 \mu \mathrm{V}, p=0.046$ ) (Fig. $6 \mathrm{~A}$ ). We did not observe any main effects of prime condition, target face, or laterality.

Three-way ANOVA (prime $\times$ target $\times$ laterality) calculated for N170 latency revealed a significant interaction between Prime Face and Laterality in female participants $\left(F(1,21)=5.04, p=0.036, \eta^{2}=0.19\right)$ (Table 2). Further analysis revealed that N170 latency in the left ROI was significantly shorter in the fearful prime condition than in the neutral prime condition $(477.82 \pm 1.50 \mathrm{~ms}$ vs. $479.68 \pm 1.62 \mathrm{~ms}, p=0.036)$. No main effects or interactions were significant for N170 latency in male participants (Table 2).

\section{P2 component}

A three-way ANOVA (prime $\times$ target $\times$ laterality) calculated for P2 amplitude revealed a significant main effect of Target Face for each gender (Males: $F(1.50,34.41)=14.53, p<0.001, \eta^{2}=0.39$, Females: $F(1.58,33.26)=4.15, p=0.023, \eta^{2}=$ 0.17) (Table 2). A direct comparison between target-face categories in male participants revealed that $P 2$ amplitudes were higher for neutral target faces than for ambiguous-fearful $(1.92 \pm 0.27 \mu \mathrm{V}$ vs. $1.74 \pm 0.26 \mu \mathrm{V}, p<0.001)$ and fearful target faces $(1.92 \pm 0.27 \mu \mathrm{V}$ vs. $1.59 \pm 0.26 \mu \mathrm{V}, p<0.001)$. In contrast, we found no significant differences among the target face categories in female participants. ANOVA also revealed a significant interaction of Target Face $\times$ Laterality in females $(F(2$, 
$\left.42)=4.10, p=0.024, \eta^{2}=0.16\right)$, and Prime Facex Laterality in males $\left(F(1,23)=6.92, p=0.015, \eta^{2}=0.23\right)($ Table 2). P2 amplitude in the female right ROI was significantly larger for ambiguous-fearful target faces than for fearful target faces $(1.96 \pm 0.24 \mu \mathrm{V}$ vs. $1.75 \pm 0.22 \mu \mathrm{V}, p=0.028)$. In contrast, $\mathrm{P} 2$ amplitude in the right male ROI was significantly larger in the fearful prime condition than in the neutral prime condition ( $1.68 \pm 0.28 \mu \mathrm{V} v \mathrm{~s}$. $1.54 \pm 0.30 \mu \mathrm{V}, p<0.05$ ) (for a time-course representation of the ERPs, see Supplementary Fig. S3). We found no main effects or interactions for P2 latency in either group (Table 2).

\section{Correlations between each ERP component and intra-participant factors in behavioural data}

Unlike the N170, the P1 and P2 components did not show significant relationships with intra-participant factors. N170 amplitude in the right hemisphere was only positively correlated with RT in the male participants $(r=0.38, p<0.001)$. N170 latency in both hemispheres was also positively correlated with RT in males (left: $r=0.55, p<0.001$, right: $r=0.50, p<$ 0.001). In females however, we did not find any significant correlations between N170 amplitude or latency and withinparticipant factors (Table 3).

\section{Discussion}

In the current study, we explored the neural correlates of SAPEs in terms of behavioural performance and high-density ERPs. We compared ERPs in response to three types of target-face stimuli (neutral, ambiguous-fearful, and fearful) after participants were primed by neutral and fearful face stimuli that were presented for only $17 \mathrm{~ms}$, and were thus subliminal. The results revealed that the rates of fearful judgments for all target faces preceded by a fearful prime-face stimulus were significantly greater than those preceded by a neutral prime-face stimulus. We also found that SAPEs for the face-specific N170 component were only evident in female participants (see Fig. 5). Interestingly, multiple regression analysis revealed that N170 amplitude and latency were significantly correlated with RTs in males but not females. These results suggest that the N170 component primarily reflects the neural basis of the SAPE, and its impact on behavioural performance may differ between genderes. Several previous studies have reported right-lateralized N170/M170-components in the occipitotemporal area in male participants, but not in female participants [41,42]. Although Choi et al. [43], reported gender differences in N170 emotional sensitivity, there have been no studies demonstrating a gender difference of SAPEs in ERPs, including the face-specific N170 component.

Our behavioural data revealed that emotional judgments of target faces were affected by subliminally presented fearful face stimuli. Although affective priming typically leads to shorter reaction times when judging targets [27,28], we did not observe such an effect. Rather, we observed longer RTs for the ambiguous-fearful target faces than for the neutral or fearful target faces. We are not certain that this finding reflects the difficulty of the emotional judgment or a negative effect of priming. Interestingly, N170 amplitude and latency positively correlated with male-participant RTs. Thus, our behavioural results indicate that subliminal perception of fearful faces biased facial judgment toward fearful. Positive correlations between RT and N170 latencies in males also suggest that early neural processing of target faces might affect how fast they can be judged.

Previous studies have demonstrated that emotional judgments of neutral objects are affected by briefly presented emotional prime faces [28,44]. In a positive (happy) prime condition, participants evaluated neutral objects more positively than they did in a neutral prime condition. Similarly, participants evaluated neutral objects more negatively in a negative (angry, fearful, or disgusted) prime condition than they did in a neutral condition. This effect was prominent in the primetarget valence-congruent condition. Furthermore, other studies have reported gender differences in the affective priming effect. Gohier et al. [37] reported greater sensitivity to negative emotional prime-face stimuli in females than in males, whereas Donges et al. [36] demonstrated stronger positive priming in females than in males. In accord with previous 
studies, our behavioural data revealed a negative priming effect of fearful faces, in which RRs for target faces primed by fearful faces were significantly higher than those primed by neutral faces. Although this result demonstrated the SAPE in the fearful prime-face condition regardless of target facial expression, we found no gender differences in any priming condition. This discrepancy between our behavioural results and those from other studies may be related to the longer durations of prime stimuli that were used in previous studies (33 ms or $250 \mathrm{~ms}$ ), given that some participants in previous studies exhibited extremely short subthresholds (<33 ms) for visual stimuli $[24,45]$.

Although our results revealed no significant main effect of laterality for the N170, we found a gender-related difference in the neural processing of target-face stimuli. Specifically, we observed larger N170 amplitudes in the right hemisphere of females in response to neutral target-face stimuli primed by fearful face stimuli compared to those primed by neutral face stimuli. In contrast, larger N170 amplitudes were found in the right ROI of males than in the left ROI when primed by fearful face stimuli. The N170 component is generated in the FFA, while the STS is considered to be specialized for visual processing and encoding of high level features such as structural information contained within faces $[1,10,46,47]$. Although some researchers $[30,48]$ have claimed that the N170 is relatively insensitive to emotion, several studies have observed the sensitivity of this component to emotional facial expressions $[13,15,49]$. Based on these controversial findings, many previous studies have examined the emotion-based modulation of the N170 component by looking for effects related to the emotional valence of prime stimuli. ERP studies using the affective priming paradigm have reported enhanced N170 amplitude for target stimuli when the emotional valence of prime visual stimuli or scenes is congruent with that of target stimuli [50-52]. Although negative evidence for affective priming effects on the N170 component has been reported [53,54], one explanation for this discrepancy between the current findings and previous studies could be the difference in SOAs. The reports of SAPEs on the subsequent supraliminally presented target face that have been demonstrated by ERP studies using the backward masking paradigm $[14,55]$ are currently inconclusive because of the overlapped ERP responses for prime and target faces. In the present study, we chose an SOA of $300 \mathrm{~ms}$ because it has been used in several previous studies [35,50,56] and has been shown to be effective for facilitating the affective priming effect. Moreover, Itier et al. [46] demonstrated a repetition effect on N170 amplitude in which repetition of the same face identity suppressed the N170 response, leading to increased N170 amplitude in prime-target incongruent conditions (e.g., different expressions of faces with the same identity or different identities). These findings further suggest that automatic rapid encoding of emotional information included in prime stimuli is implemented in the brain, and that such information is integrated with the emotional content of subsequent target stimuli by the FFA, STS, or OFA. From this perspective, the N170 modulation observed in female participants could be considered a prime-target incongruent repetition effect. However, it remains unclear why this effect was not observed in male participants, and why other prime-target incongruent pairs did not show repetition effects.

Because the presentation duration in the current study was extremely short (17 ms), it also remains unclear whether subliminal emotional properties were processed in the occipito-temporal face-sensitive areas. We assume that the gender differences we observed in the N170 can be partially explained by the functional connectivity between the FFA and amygdala [57,58]. Evolutionarily, unconscious processing of threat-related stimuli should be beneficial because it allows extremely rapid motor responses to the stimuli [17]. The amygdala is involved in pre-attentive, rapid processing of threatrelated stimuli, whereby it receives subcortical visual information via the superior colliculus and pulvinar thalamus[19], and anatomical evidence for subcortical emotional pathway connections has also been shown in nonhuman primates and humans [21].The sensitivity of the amygdala to emotional content has generally been investigated using the phenomenon by which subliminally presented emotional visual stimuli enhance amygdala activation [59-61]. A previous study reported that the amygdala appears to be involved in automatically elicited negative evaluative shifts in response to negative face priming [62]. Because the modulation of the visual cortex by emotional face stimuli is dependent on the amygdala [63,64], it is possible that modulation of N170 amplitude reflects the contribution of amygdala output to the visual cortex [63]. Dima et al. [65] suggested that negative emotional information is conveyed to the ventral prefrontal cortex (VPFC) via multiple pathways, including the inferior occipital gyrus, FFA, and the amygdala, and is processed among these pathways in 
parallel. In addition, functional magnetic resonance imaging (fMRI) studies have reported gender differences in the processing of emotional properties in which females exhibited enhanced activity in emotion-specific areas such as the amygdala, the orbitofrontal cortex, and the anterior cingulate cortex in response to negative stimuli. In males, cognition and cognitive control areas such as the prefrontal and superior parietal regions were recruited to process negative content, while the amygdala showed attenuated activation $[66,67]$. Taken together, we speculate that in females, subliminally-presented fearful face stimuli in the fearful prime-neutral target condition activate emotion-specific areas including the amygdala. These areas then stimulate the FFA and process neutral target faces as emotionally negative (enhanced N170 amplitude). In males however, subliminally perceived fearful-face information is conveyed to the VPFC via the amygdala and subsequent target faces are cognitively processed.

Although previous studies reported prime-target emotional incongruency effects on P1 [54,68], the present study failed to demonstrate SAPEs in the P1 and P2 components, despite the emotional sensitivity shown by these components. In previous studies, P1 amplitude was reported to be enhanced by fearful faces significantly more than by happy or neutral faces, while the frontal N1, as the counterpart to the P1, was modulated by passive viewing of emotional expressions $[69,70]$. Similarly, previous studies have reported larger P2 amplitudes for face stimuli with configuration modifications than for faces with feature modifications or the original faces [71]. Thus, P1 is thought to exhibit rapid responses to threatrelated stimuli, while $\mathrm{P} 2$ reflects the initial stages of facial expression cognition, regardless of preceding emotional stimuli.

Our study has some methodological limitations. First. it lacked a control condition. We might have overlooked other SAPEs (both behavioural and electrophysiological) because we did not compare the prime condition with a primeless condition. Second, we only studied the emotion of fear. Are SAPEs solely evident in the fearful face-priming condition? We are therefore cautious about how to interpret the SAPEs we observed. In the future, we need to use both subliminal priming and primeless conditions and include other prime and target faces (i.e., happy, sad, angry, and disgusted faces). Third, although the intensity levels for male and female face images were almost equal (see SI.2), the number of face stimuli used in our study was small. Because the ATR face database contains 4 female and 6 male actors, and because we wanted the number of male/female faces to be equal, we were limited to 4 female and 4 male face images. Furthermore, we did not consider individual face actors as fixed factors. Kret et al.[72] reported that males showed higher brain activity in several regions of interest, including FFA and STS, following fearful and angry male bodily expressions. Further analysis will be necessary to determine the effect of 'face actor' on SAPEs.

Finally, a current study revealed that SAPEs were more pronounced in the fearful prime-neutral target condition in females. However, we failed to find a significant interaction between prime and target conditions in males, even using the ambiguous-fearful target face, which we expected to show salient SAPEs. Further study will be necessary to consider these problems.

\section{Conclusions}

In the current study, female participants exhibited increased N170 amplitude in neutral prime trials with fearful target faces, whereas male participants exhibited increased N170 amplitude in the right ROI in all fearful prime conditions. Significant positive correlations between ERPs and behavioural performance were observed only in male participants. Our ERP results suggest the existence of a gender difference in target-face processing preceded by subliminally presented face stimuli in the right occipito-temporal regions.

\section{Abbreviations}

SAPEs: subliminal affective priming effects; ERPs: event-related potentials; OFA: occipital face area; FFA: fusiform face area; STS: the superior temporal sulcus; SOA: stimulus onset asynchrony; EEG: electroencephalogram; SI: supplementary information; RR: response rate; RT: reaction time; MST: microstate analysis toolbox; GEV: global explained variance; CV: 
cross-validation; K-L: Krzanowski-Lai; ANOVA: analysis of variance; ROI: region of interests; VPFC: ventral prefrontal cortex; fMRI: functional magnetic resonance imaging.

\section{Declarations}

\section{Ethics approval and consent to participants}

This study was carried according to the Declaration of Helsinki and the Guideline for Good Clinical Practice. The experimental procedure was approved by the Ethics Committee at the Graduate School of Medical Science, Kyushu University (24078). All participants signed an informed consent.

\section{Consent to publish}

Not applicable

\section{Availability of data and materials}

The dataset used or analyzed during the current study are available from the corresponding author on reasonable request.

\section{Competing Interests}

The authors declare no competing interests.

\section{Funding}

This study was supported in part by a JSPS KAKENHI Grant-in-Aid for Exploratory Research, "Subliminal affective priming effects for subcortical emotional pathway" (26560295) and a Grant-in-Aid for Scientific Research on Innovative Areas MEXT KAKENHI $15 \mathrm{H} 05875$.

\section{Author Contributions}

MT, TM, EY, NT, and ST conceived and designed the experiments. KO, EY, and HN contributed experimental programs and analysis tools. MT performed the experiments and analysed the data. MT, TM, KO, EY, NT, and ST wrote the paper. The study was supervised by TM and ST. 


\section{Acknowledgments}

We thank Benjamin Knight, MSc and Adam Phillips, PhD, from Edanz Group (www.edanzediting.com/ac) for editing a draft of this manuscript.

\section{References}

1. Bruce V, Young A. Understanding face recognition. Br J Psychol. 1986;77(3):305-27.

2. Eimer M. The face-specific N170 component reflects late stages in the structural encoding of faces. Neuroreport [Internet]. 2000;11(10):2319-24. Available from: http://content.wkhealth.com/linkback/openurl?sid = WKPTLP:landingpage\&an $=00001756-200007140-00050$

3. Itier RJ. N170 or N1? Spatiotemporal Differences between Object and Face Processing Using ERPs. Cereb Cortex [Internet]. 2004 Feb 1 [cited 2011 Jun 23];14(2):132-42. Available from: http://www.cercor.oupjournals.org/cgi/doi/10.1093/cercor/bhg111

4. Gentile F, Ales J, Rossion B. Being BOLD: The neural dynamics of face perception. Hum Brain Mapp. 2017;38(1):12039.

5. Jonas J, Jacques C, Liu-Shuang J, Brissart H, Colnat-Coulbois S, Maillard L, et al. A face-selective ventral occipitotemporal map of the human brain with intracerebral potentials. Proc Natl Acad Sci [Internet]. 2016;113(28):E4088-97. Available from: http://www.pnas.org/lookup/doi/10.1073/pnas.1522033113

6. Rossion B, Joyce CA, Cottrell GW, Tarr MJ. Early lateralization and orientation tuning for face, word, and object processing in the visual cortex. Neuroimage. 2003;20(3):1609-24.

7. Kanwisher N, McDermott J, Chun MM. The fusiform face area: a module in human extrastriate cortex specialized for face perception. J Neurosci [Internet]. 1997;17(11):4302-11. Available from:

http://www.ncbi.nlm.nih.gov/pubmed/9151747

8. Haxby J V, Hoffman E a, Gobbini MI. The distributed human neural system for face perception [Record Supplied By Publisher]. Trends Cogn Sci. 2000;4(6):223-33.

9. Dering B, Martin CD, Moro S, Pegna AJ, Thierry G. Face-Sensitive Processes One Hundred Milliseconds after Picture Onset. Front Hum Neurosci [Internet]. 2011;5(September):1-14. Available from:

http://journal.frontiersin.org/article/10.3389/fnhum.2011.00093/abstract

10. Bentin S, Allison T, Puce A, Perez E, McCarthy G. Electrophysiological Studies of Face Perception in Humans. J Cogn Neurosci [Internet]. 1996 Nov;8(6):551-65. Available from: http://www.pubmedcentral.nih.gov/articlerender.fcgi?artid = 2927138\&tool $=$ pmcentrez\&rendertype $=$ abstract

11. Deffke I, Sander T, Heidenreich J, Sommer W, Curio G, Trahms L, et al. MEG/EEG sources of the 170-ms response to faces are co-localized in the fusiform gyrus. Neuroimage. 2007;35(4):1495-501.

12. Nguyen VT, Cunnington R. The superior temporal sulcus and the N170 during face processing: Single trial analysis of concurrent EEG-fMRI. Neuroimage [Internet]. 2014;86:492-502. Available from:

http://dx.doi.org/10.1016/j.neuroimage.2013.10.047

13. Batty M, Taylor MJ. Early processing of the six basic facial emotional expressions. Cogn Brain Res. 2003;17(3):61320.

14. Pegna AJ, Landis T, Khateb A. Electrophysiological evidence for early non-conscious processing of fearful facial expressions. Int J Psychophysiol [Internet]. 2008 Nov [cited 2011 Aug 6];70(2):127-36. Available from: http://www.ncbi.nlm.nih.gov/pubmed/18804496

15. Hinojosa JA, Mercado F, Carretié L. N170 sensitivity to facial expression: A meta-analysis. Neurosci Biobehav Rev [Internet]. 2015;55:498-509. Available from:

http://linkinghub.elsevier.com/retrieve/pii/S0149763415001566\%5Cnhttp://www.ncbi.nlm.nih.gov/pubmed/26067902 
16. Celeghin A, Diano M, Bagnis A, Viola M, Tamietto M. Basic emotions in human neuroscience: Neuroimaging and beyond. Front Psychol. 2017;8(AUG):1-13.

17. Costa T, Cauda F, Crini M, Tatu MK, Celeghin A, De Gelder B, et al. Temporal and spatial neural dynamics in the perception of basic emotions from complex scenes. Soc Cogn Affect Neurosci. 2014;9(11):1690-703.

18. Bayle DJ, Henaff M-A, Krolak-Salmon P. Unconsciously perceived fear in peripheral vision alerts the limbic system: a MEG study. PLoS One [Internet]. 2009 Jan [cited 2011 Aug 5];4(12):e8207. Available from:

http://www.pubmedcentral.nih.gov/articlerender.fcgi? artid = 2785432\&tool = pmcentrez\&rendertype = abstract

19. Öhman A, Carlsson K, Lundqvist D, Ingvar M. On the unconscious subcortical origin of human fear. Physiol Behav. 2007;92(1-2):180-5.

20. Ruggeri P, Meziane HB, Koenig T, Brandner C. A fine-grained time course investigation of brain dynamics during conflict monitoring. Sci Rep. 2019 Dec 1;9(1).

21. Tamietto M, Pullens P, De Gelder B, Weiskrantz L, Goebel R. Subcortical connections to human amygdala and changes following destruction of the visual cortex. Curr Biol. 2012;22(15):1449-55.

22. Morris JS. Differential extrageniculostriate and amygdala responses to presentation of emotional faces in a cortically blind field. Brain. 2001;124(6):1241-52.

23. Vuilleumier P, Armony J., Clarke K, Husain M, Driver J, Dolan R. Neural response to emotional faces with and without awareness: event-related $\mathrm{fMRI}$ in a parietal patient with visual extinction and spatial neglect. Neuropsychologia [Internet]. 2002 Jan 1 [cited 2019 Jul 23];40(12):2156-66. Available from:

https://www.sciencedirect.com/science/article/pii/S0028393202000453

24. Mitsudo T, Kamio Y, Goto Y, Nakashima T, Tobimatsu S. Neural responses in the occipital cortex to unrecognizable faces. Clin Neurophysiol [Internet]. 2011 Apr [cited 2011 Aug 3];122(4):708-18. Available from:

http://www.ncbi.nIm.nih.gov/pubmed/21071267

25. Van den Stock J, Tamietto M, Sorger B, Pichon S, Grezes J, de Gelder B. Cortico-subcortical visual, somatosensory, and motor activations for perceiving dynamic whole-body emotional expressions with and without striate cortex (V1). Proc Natl Acad Sci. 2011;108(39):16188-93.

26. Diano M, Celeghin A, Bagnis A, Tamietto M. Amygdala response to emotional stimuli without awareness: Facts and interpretations. Front Psychol. 2017;7(JAN):1-13.

27. Fazio RH. On the automatic activation of associated evaluations: An overview. Cogn Emot [Internet]. 2001 Mar 1;15(2):115-41. Available from: https://www.tandfonline.com/doi/abs/10.1080/02699930125908

28. Murphy ST, Zajonc RB. Affect, cognition, and awareness; affective priming with optimal and suboptimal stimulus exposures. J Personal Soc Psychol [Internet]. 1993;64(5):723-39. Available from:

http://www.ncbi.nlm.nih.gov/sites/entrez?Db = pubmed\&DbFrom = pubmed\&Cmd = Link\&LinkName = pubmed_pubmed\&LinkReadableName $=$ Related Articles\&IdsFromResult $=8505704 \&$ ordinalpos $=3 \&$ itool $=$ EntrezSystem2.PEntrez.Pubmed.Pubmed_ResultsPanel.Pubmed_RVDocSum

29. Axelrod V, Bar M, Rees G. Exploring the unconscious using faces. Trends Cogn Sci [Internet]. 2015;19(1):35-45. Available from: http://dx.doi.org/10.1016/j.tics.2014.11.003

30. Kiss M, Eimer M. ERPs reveal subliminal processing of fearful faces. Psychophysiology [Internet]. 2008 Mar [cited 2011 Jul 12];45(2):318-26. Available from: http://www.pubmedcentral.nih.gov/articlerender.fcgi? artid $=2375009 \&$ tool = pmcentrez\&rendertype = abstract

31. Li W, Zinbarg RE, Boehm SG, Paller K a. Neural and behavioral evidence for affective priming from unconsciously perceived emotional facial expressions and the influence of trait anxiety. J Cogn Neurosci [Internet]. 2008 Jan;20(1):95-107. Available from: http://www.ncbi.nlm.nih.gov/pubmed/17919076

32. Liddell BJ, Williams LM, Rathjen J, Shevrin H, Gordon E. A temporal dissociation of subliminal versus supraliminal fear perception: an event-related potential study. J Cogn Neurosci [Internet]. 2004 Apr;16(3):479-86. Available from: 
http://www.ncbi.nIm.nih.gov/pubmed/15072682

33. Vukusic S, Ciorciari J, Crewther DP. Electrophysiological Correlates of Subliminal Perception of Facial Expressions in Individuals with Autistic Traits: A Backward Masking Study. Front Hum Neurosci [Internet]. 2017;11:256. Available from: http://www.ncbi.nlm.nih.gov/pubmed/28588465\%5Cnhttp://www.ncbi.nlm.nih.gov/pubmed/28588465

34. Pegna AJ, Darque A, Berrut C, Khateb A. Early ERP modulation for task-irrelevant subliminal faces. Front Psychol. 2011;2(MAY):1-10.

35. Fazio RH, Sanbonmatsu DM, Powell MC, Kardes FR. On the Automatic Activation of Attitudes. J Pers Soc Psychol. 1986;50(2):229-38.

36. Donges US, Kersting A, Suslow T. Women's greater ability to perceive happy facial emotion automatically: Gender differences in affective priming. PLoS One. 2012;7(7):1-5.

37. Gohier B, Senior C, Brittain PJ, Lounes N, El-Hage W, Law V, et al. Gender differences in the sensitivity to negative stimuli: Cross-modal affective priming study. Eur Psychiatry [Internet]. 2013;28(2):74-80. Available from: http://dx.doi.org/10.1016/j.eurpsy.2011.06.007

38. Cacioppo S, Weiss RM, Cacioppo JT. Dynamic spatiotemporal brain analyses of the visual checkerboard task: Similarities and differences between passive and active viewing conditions. Psychophysiology. 2016;53(10):1496506.

39. Poulsen AT, Pedroni A, Langer N, Hansen LK. Draft: Microstate EEGlab toolbox: An introductional guide. bioRxiv. 2018;1-29.

40. Delorme A, Makeig S. EEGLAB: An open source toolbox for analysis of single-trial EEG dynamics including independent component analysis. J Neurosci Methods. 2004;134(1):9-21.

41. Proverbio AM, Riva F, Martin E, Zani A. Face coding is bilateral in the female brain. PLoS One. 2010;5(6):6-12.

42. Tiedt HO, Weber JE, Pauls A, Beier KM, Lueschow A. Sex-differences of face coding: evidence from larger right hemispheric M170 in men and dipole source modelling. PLoS One [Internet]. 2013 Jan [cited 2014 May 8];8(7):e69107. Available from: http://www.pubmedcentral.nih.gov/articlerender.fcgi? artid $=3706449 \&$ tool $=$ pmcentrez\&rendertype $=$ abstract

43. Choi D, Egashira Y, Takakura J, Motoi M, Nishimura T, Watanuki S. Gender difference in N170 elicited under oddball task. J Physiol Anthr. 2015;34(1):7.

44. Winkielman P, Berridge KC, Wilbarger JL. Unconscious affective reactions to masked happy versus angry faces influence consumption behavior and judgments of value. Personal Soc Psychol Bull. 2005;31(1):121-35.

45. Pessoa L. To what extent are emotional visual stimuli processed without attention and awareness? Curr Opin Neurobiol [Internet]. 2005 Apr [cited 2011 Jul 19];15(2):188-96. Available from:

http://www.ncbi.nlm.nih.gov/pubmed/15831401

46. Itier RJ, Taylor MJ. Inversion and contrast polarity reversal affect both encoding and recognition processes of unfamiliar faces: A repetition study using ERPs. Neuroimage. 2002;15(2):353-72.

47. Rossion B. Understanding face perception by means of human electrophysiology. Trends Cogn Sci. 2014;18(6):310-8.

48. Eimer M, Holmes A. An ERP study on the time course of emotional face processing. Neuroreport [Internet]. 2002 Mar 25;13(4):427-31. Available from: http://www.ncbi.nlm.nih.gov/pubmed/11930154

49. Aguado L, Dieguez-Risco T, Méndez-Bértolo C, Pozo M a, Hinojosa J a. Priming effects on the N400 in the affective priming paradigm with facial expressions of emotion. Cogn Affect Behav Neurosci [Internet]. 2013;13(2):284-96. Available from: http://www.ncbi.nlm.nih.gov/pubmed/23263839

50. Hietanen JK, Astikainen P. N170 response to facial expressions is modulated by the affective congruency between the emotional expression and preceding affective picture. Biol Psychol [Internet]. 2012 Nov [cited 2012 Nov 4];1-11. Available from: http://linkinghub.elsevier.com/retrieve/pii/S0301051112002256 
51. Righart R, De Gelder B. Context influences early perceptual analysis of faces - An electrophysiological study. Cereb Cortex. 2006;16(9):1249-57.

52. Righart R, de Gelder B. Rapid influence of emotional scenes on encoding of facial expressions: An ERP study. Soc Cogn Affect Neurosci. 2008;3(3):270-8.

53. Krombholz A, Schaefer F, Boucsein W. Modification of N170 by different emotional expression of schematic faces. Biol Psychol. 2007;76(3):156-62.

54. Werheid K, Alpay G, Jentzsch I, Sommer W. Priming emotional facial expressions as evidenced by event-related brain potentials. Int J Psychophysiol [Internet]. 2005 Feb [cited 2012 Mar 4];55(2):209-19. Available from: http://www.ncbi.nlm.nih.gov/pubmed/15649552

55. Smith ML. Rapid Processing of Emotional Expressions without Conscious Awareness. Cereb Cortex [Internet]. 2011 Sep 27 [cited 2011 Oct 4]; Available from: http://www.ncbi.nlm.nih.gov/pubmed/21955918

56. Hermans Frank Baeyens Paul Eelen D. Odours as Affective-processing Context for Word Evaluation: A Case of Crossmodal Affective Priming. Cogn Emot [Internet]. 1998 Jul 1;12(4):601-13. Available from: http://www.tandfonline.com/doi/abs/10.1080/026999398379583

57. Pessoa L, McKenna M, Gutierrez E, Ungerleider LG. Neural processing of emotional faces requires attention. Proc Natl Acad Sci [Internet]. 2002;99(17):11458-63. Available from: http://www.pnas.org/cgi/doi/10.1073/pnas.172403899

58. Vuilleumier $P$, Pourtois $G$. Distributed and interactive brain mechanisms during emotion face perception: evidence from functional neuroimaging. Neuropsychologia [Internet]. 2007 Jan 7 [cited 2012 Mar 1];45(1):174-94. Available from: http://www.ncbi.nlm.nih.gov/pubmed/16854439

59. Tamietto M, de Gelder B. Neural bases of the non-conscious perception of emotional signals. Nat Rev Neurosci [Internet]. 2010 Oct [cited 2013 May 21];11(10):697-709. Available from:

http://www.ncbi.nIm.nih.gov/pubmed/20811475

60. Pourtois G, Schettino A, Vuilleumier P. Brain mechanisms for emotional influences on perception and attention: what is magic and what is not. Biol Psychol [Internet]. 2013 Mar [cited 2014 May 1];92(3):492-512. Available from: http://www.ncbi.nIm.nih.gov/pubmed/22373657

61. Whalen PJ, Rauch SL, Etcoff NL, Mclnerney SC, Lee MB, Jenike M a. Masked presentations of emotional facial expressions modulate amygdala activity without explicit knowledge. J Neurosci [Internet]. 1998 Jan 1;18(1):411-8. Available from: http://www.ncbi.nlm.nih.gov/pubmed/9412517

62. Suslow T, Kugel H, Ohrmann P, Stuhrmann A, Grotegerd D, Redlich R, et al. Neural correlates of affective priming effects based on masked facial emotion: an fMRI study. Psychiatry Res [Internet]. 2013 Mar 30 [cited 2014 Apr 29];211(3):239-45. Available from: http://www.ncbi.nlm.nih.gov/pubmed/23131525

63. Vuilleumier P, Richardson MP, Armony JL, Driver J, Dolan RJ. Distant influences of amygdala lesion on visual cortical activation during emotional face processing. Nat Neurosci. 2004;7(11):1271-8.

64. Hadj-Bouziane F, Liu N, Bell AH, Gothard KM, Luh W-M, Tootell RBH, et al. Amygdala lesions disrupt modulation of functional MRI activity evoked by facial expression in the monkey inferior temporal cortex. Proc Natl Acad Sci [Internet]. 2012;109(52):E3640-8. Available from: http://www.pnas.org/cgi/doi/10.1073/pnas.1218406109

65. Dima D, Stephan KE, Roiser JP, Friston KJ, Frangou S. Effective Connectivity during Processing of Facial Affect: Evidence for Multiple Parallel Pathways. J Neurosci [Internet]. 2011;31(40):14378-85. Available from: http://www.jneurosci.org/cgi/doi/10.1523/JNEUROSCI.2400-11.2011

66. Domes G, Schulze L, B??ttger M, Grossmann A, Hauenstein K, Wirtz PH, et al. The neural correlates of sex differences in emotional reactivity and emotion regulation. Hum Brain Mapp. 2010;31(5):758-69.

67. Koch K, Pauly K, Kellermann T, Seiferth NY, Reske M, Backes V, et al. Gender differences in the cognitive control of emotion: An fMRI study. Neuropsychologia. 2007;45(12):2744-54. 
68. Meeren HKM, van Heijnsbergen CCRJ, de Gelder B. Rapid perceptual integration of facial expression and emotional body language. Proc Natl Acad Sci. 2005;102(45):16518-23.

69. Luo W, Feng W, He W, Wang NY, Luo YJ. Three stages of facial expression processing: ERP study with rapid serial visual presentation. Neuroimage [Internet]. 2010;49(2):1857-67. Available from:

http://dx.doi.org/10.1016/j.neuroimage.2009.09.018

70. Foti D, Hajcak G, Dien J. Differentiating neural responses to emotional pictures: Evidence from temporal-spatial PCA. Psychophysiology [Internet]. 2009 May [cited 2012 Nov 11];46(3):521-30. Available from: http://doi.wiley.com/10.1111/j.1469-8986.2009.00796.x

71. Mercure E, Dick F, Johnson MH. Featural and configural face processing differentially modulate ERP components. Brain Res [Internet]. 2008 Nov 6 [cited 2015 Jun 2];1239:162-70. Available from: http://www.ncbi.nlm.nih.gov/pubmed/18722354

72. Kret ME, Pichon S, Grèzes J, de Gelder B. Men fear other men most: Gender specific brain activations in perceiving threat from dynamic faces and bodies-an fMRI study. Front Psychol. 2011;2(JAN):1-11.

\section{Tables}

Table 1. Three-way repeated measures ANOVA results for the behavioural data

\begin{tabular}{|c|c|c|c|c|c|c|c|}
\hline \multicolumn{5}{|c|}{$\mathrm{RR}$} & \multicolumn{3}{|l|}{ RT } \\
\hline Factor & $\mathrm{df}$ & $\mathrm{F}$ & $\eta^{2}$ & $\mathrm{P}$ & df & $\eta^{2}$ & $\mathrm{P}$ \\
\hline Prime face & 1,44 & 4.45 & 0.09 & 0.04 & 1,44 & 0.070 .00 & 0.07 \\
\hline Target face & \multicolumn{4}{|c|}{$1.28,56.60762 .790 .95 \mathrm{p}<0.001$} & \multicolumn{3}{|c|}{$1.41,62.1611 .110 .20 \mathrm{p}<0.001$} \\
\hline Gender & 1,44 & 1.4 & & 0.24 & 1,44 & 0 & 0.96 \\
\hline Prime face $\times$ & $1.70,74.99$ & 0.5 & 0.01 & 0.53 & 2,88 & 0.270 .01 & 0.76 \\
\hline \multicolumn{8}{|l|}{ Target face } \\
\hline Prime face $x$ & 1,44 & 12.4 & 0.04 & 0.20 & 1,44 & 0.520 .01 & 0.48 \\
\hline \multicolumn{8}{|l|}{ Gender } \\
\hline Target face $x$ & $1.28,56.60$ & 2.4 & 0.05 & 0.09 & $1.41,62.16$ & 1.260 .03 & 0.28 \\
\hline \multicolumn{8}{|l|}{ Gender } \\
\hline Prime face $x$ & $1.70,74.99$ & 0.0 & 0.00 & 0.89 & 2,88 & 0.060 .00 & 0.95 \\
\hline \multicolumn{8}{|c|}{ Target face $x$} \\
\hline Gender & & & & & & & \\
\hline
\end{tabular}

Prime faces comprised fearful and neutral faces displayed by four Japanese actors (two males and two females). Target faces comprised fearful, ambiguous-fearful, and neutral faces displayed by four Japanese actors (two males and two females), who were not the same actors used for the Prime faces.

Abbreviations: RR, the fearful response rate; RT, reaction time. 
Bold values indicate $p<0.05$ in this table and subsequent tables.

Table 2. Four-way repeated measures ANOVA results for the P1, N170 and P2 components 


\begin{tabular}{|c|c|c|c|c|c|c|c|c|}
\hline \multirow[b]{2}{*}{ Factor } & \multicolumn{4}{|c|}{ Amplitude } & \multicolumn{4}{|c|}{ Latency } \\
\hline & $\mathrm{df}$ & $F$ & $\eta^{2}$ & $P$ & $\mathrm{df}$ & F & $\eta^{2}$ & $P$ \\
\hline \multicolumn{9}{|l|}{ P1 } \\
\hline Prime face & 1,23 & 0.02 & 0.00 & 0.89 & 1,23 & 0.58 & 0.03 & 0.45 \\
\hline Target face & 2,46 & 8.31 & 0.27 & 0.00 & 2,46 & 0.62 & 0.03 & 0.54 \\
\hline Laterality & 1,23 & 11.36 & 0.33 & 0.00 & 1,23 & 2.65 & 0.10 & 0.12 \\
\hline \multicolumn{9}{|l|}{ N170 } \\
\hline Prime face & 1,23 & 0.17 & 0.01 & 0.69 & 1,23 & 1.73 & 0.07 & 0.20 \\
\hline Target face & $1.52,34.93$ & 0.59 & 0.03 & 0.56 & 2,46 & 0.12 & 0.01 & 0.88 \\
\hline Laterality & 1,23 & 0.42 & 0.03 & 0.42 & 1,23 & 0.00 & 0.00 & 0.96 \\
\hline Prime face $x$ & 1,23 & 12.29 & 0.35 & 0.00 & & & & \\
\hline \multicolumn{9}{|l|}{ Laterality } \\
\hline \multicolumn{9}{|l|}{ P2 } \\
\hline Prime face & 1,23 & 2.76 & 0.11 & 0.11 & 1,23 & 0.73 & 0.03 & 0.40 \\
\hline Target face & $1.50,34.41$ & 14.53 & 0.39 & 0.00 & 2,46 & 0.24 & 0.01 & 0.79 \\
\hline Laterality & 1,21 & 2.78 & 0.11 & 0.11 & 1,23 & 1.02 & 0.04 & 0.32 \\
\hline Prime face $x$ & 1,23 & 6.92 & 0.23 & 0.02 & & & & \\
\hline Laterality & & & & & & & & \\
\hline
\end{tabular}

\section{Females}

\begin{tabular}{|c|c|c|c|c|c|c|c|c|}
\hline \multirow[b]{2}{*}{ Factor } & \multicolumn{4}{|c|}{ Amplitude } & \multicolumn{4}{|c|}{ Latency } \\
\hline & $\mathrm{df}$ & $F$ & $\eta^{2}$ & $P$ & $\mathrm{df}$ & $\mathrm{F}$ & $\eta^{2}$ & $P$ \\
\hline \multicolumn{9}{|l|}{ P1 } \\
\hline Prime face & 1,21 & 1.23 & 0.06 & 0.28 & 1,21 & 0.19 & 0.01 & 0.67 \\
\hline Target face & 2,42 & 8.79 & 0.30 & 0.00 & 2,42 & 0.51 & 0.02 & 0.60 \\
\hline Laterality & 1,21 & 2.35 & 0.10 & 0.14 & 1,21 & 5.27 & 0.20 & 0.03 \\
\hline \multicolumn{9}{|l|}{ N170 } \\
\hline Prime face & 1,21 & 0.10 & 0.01 & 0.76 & 1,21 & 3.02 & 0.13 & 0.10 \\
\hline Target face & 2,42 & 0.39 & 0.02 & 0.68 & 2,42 & 0.17 & 0.01 & 0.84 \\
\hline Laterality & 1,21 & 0.19 & 0.01 & 0.67 & 1,21 & 2.25 & 0.10 & 0.15 \\
\hline Prime face $\times$ & & & & & 1,21 & 5.04 & 0.19 & 0.04 \\
\hline \multicolumn{9}{|l|}{ Laterality } \\
\hline Prime face $\times$ & 2,42 & 4.88 & 0.19 & 0.01 & & & & \\
\hline
\end{tabular}


Target face $x$

\begin{tabular}{|c|c|c|c|c|c|c|c|c|}
\hline Laterality & & & & & & & & \\
\hline \multicolumn{9}{|l|}{ P2 } \\
\hline Prime face & 1,23 & 1.26 & 0.06 & 0.27 & 1,21 & 0.01 & 0.00 & 0.94 \\
\hline Target face & $1.58,33.26$ & 4.15 & 0.17 & 0.02 & 2,42 & 2.36 & 0.10 & 0.11 \\
\hline Laterality & 1,21 & 3.67 & 0.15 & 0.07 & 1,21 & 0.58 & 0.03 & 0.45 \\
\hline Target face $x$ & 2,42 & 4.10 & 0.16 & 0.02 & & & & \\
\hline Laterality & & & & & & & & \\
\hline
\end{tabular}

Table 3. Relationships between intra-subject factors (prime face category and target face category) and ERP components 
Males

\begin{tabular}{|c|c|c|c|c|c|c|c|c|}
\hline & \multicolumn{4}{|c|}{ Left } & \multicolumn{4}{|c|}{ Right } \\
\hline & $R^{\dagger}$ & $p$ & $R^{2 \ddagger}$ & $p$ & $r$ & $p$ & $R^{2}$ & $p$ \\
\hline \multicolumn{9}{|c|}{ N170 amplitudes } \\
\hline $\mathrm{RR}$ & 0.02 & n.s. & & & 0.01 & n.s. & & \\
\hline $\mathrm{RT}$ & -0.04 & n.s. & & & 0.38 & $<0.001$ & 0.15 & $<0.001 * *$ \\
\hline Prime & -0.03 & n.s. & & & 0.04 & n.s. & & \\
\hline \multirow[t]{3}{*}{ Target } & 0.03 & n.s. & & & 0.02 & n.s. & & \\
\hline & \multicolumn{4}{|c|}{ Left } & \multicolumn{4}{|c|}{ Right } \\
\hline & $r$ & $p$ & $R^{2}$ & $p$ & $r$ & $p$ & $R^{2}$ & $p$ \\
\hline \multicolumn{9}{|c|}{ N170 latencies } \\
\hline $\mathrm{RR}$ & 0.00 & n.s. & & & 0.03 & n.s. & & \\
\hline $\mathrm{RT}$ & 0.55 & $<0.001$ & 0.30 & $<0.001 * *$ & 0.50 & $<0.001$ & 0.25 & $<0.001 * *$ \\
\hline Prime & -0.02 & n.s. & & & -0.02 & n.s. & & \\
\hline Target & 0.02 & n.s. & & & 0.03 & n.s. & & \\
\hline
\end{tabular}

Females

\begin{tabular}{|c|c|c|c|c|c|c|c|c|}
\hline & \multicolumn{4}{|c|}{ Left } & \multicolumn{4}{|c|}{ Right } \\
\hline & $r$ & $p$ & $R^{2}$ & $p$ & $r$ & $p$ & $R^{2}$ & $p$ \\
\hline \multicolumn{9}{|c|}{ N170 amplitudes } \\
\hline $\mathrm{RR}$ & -0.02 & n.s. & & & 0.01 & n.s. & & \\
\hline $\mathrm{RT}$ & -0.02 & n.s. & & & -0.03 & n.s. & & \\
\hline Prime & 0.02 & n.s. & & & -0.01 & n.s. & & \\
\hline \multirow[t]{3}{*}{ Target } & 0.01 & n.s. & & & -0.01 & n.s. & & \\
\hline & \multicolumn{4}{|c|}{ Left } & \multicolumn{4}{|c|}{ Right } \\
\hline & $r$ & $p$ & $R^{2}$ & $p$ & $r$ & $p$ & $R^{2}$ & $p$ \\
\hline \multicolumn{9}{|c|}{ N170 latencies } \\
\hline $\mathrm{RR}$ & 0.05 & n.s. & & & 0.00 & n.s. & & \\
\hline $\mathrm{RT}$ & 0.08 & n.s. & & & 0.00 & n.s. & & \\
\hline Prime & -0.06 & n.s. & & & -0.01 & n.s. & & \\
\hline Target & -0.01 & n.s. & & & 0.02 & n.s. & & \\
\hline
\end{tabular}

$* p<0.05, * * p<0.01, \dagger$ Pearson’s correlation, $\neq$ Multiple correlation from stepwise regression analysis 
A

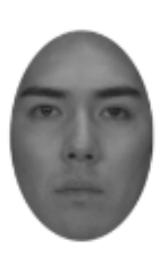

Neutral face

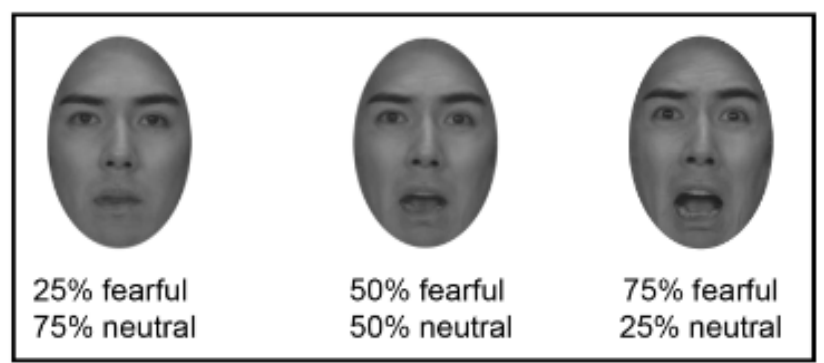

Ambiguous fearful face

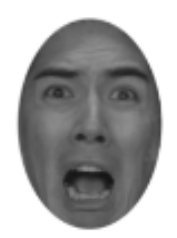

Fearful face

B

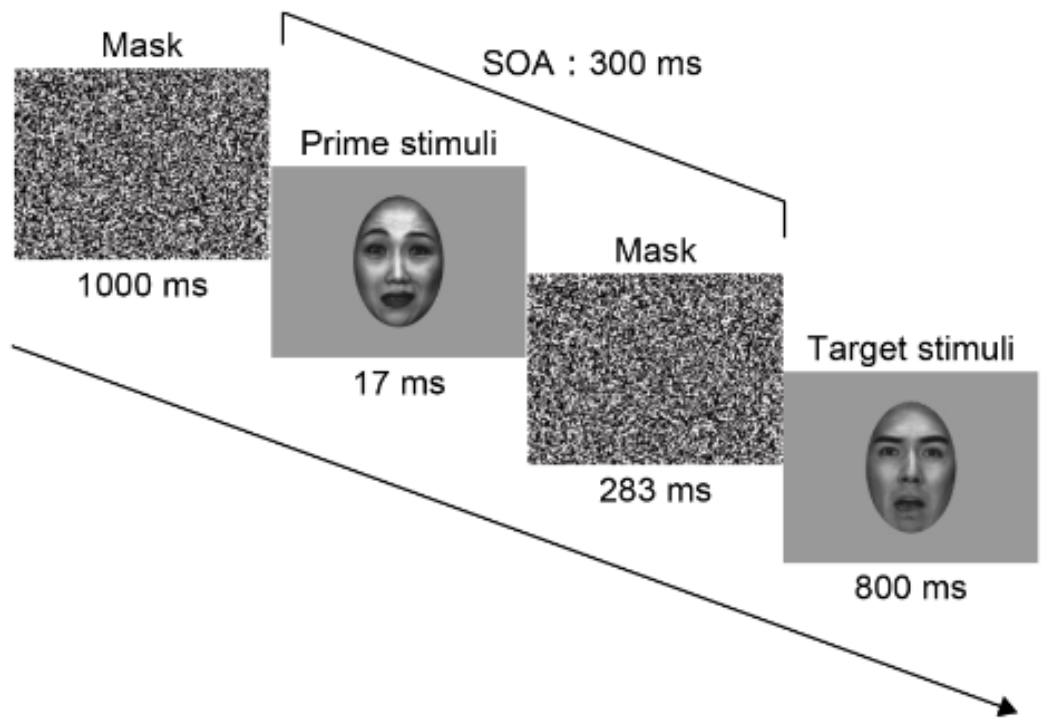

Figure 1

Behavioural results for response rates (RRs) and reaction times (RTs). RRs for the fearful face-priming condition were significantly higher than those for the neutral face-priming condition (A). RRs for fearful target-face stimuli were significantly higher than those for neutral and ambiguous-fearful target faces (B). RRs for ambiguous-fearful target faces were also significantly higher than those for neutral target faces. Gender differences were not significant. Reaction times (RTs) for the ambiguous-fearful target-face stimuli were significantly higher than those for neutral and fearful target faces (C). Error bars represent the SEM. ${ }^{*} p<0.0 .5,{ }^{* *} p<0.01$ 


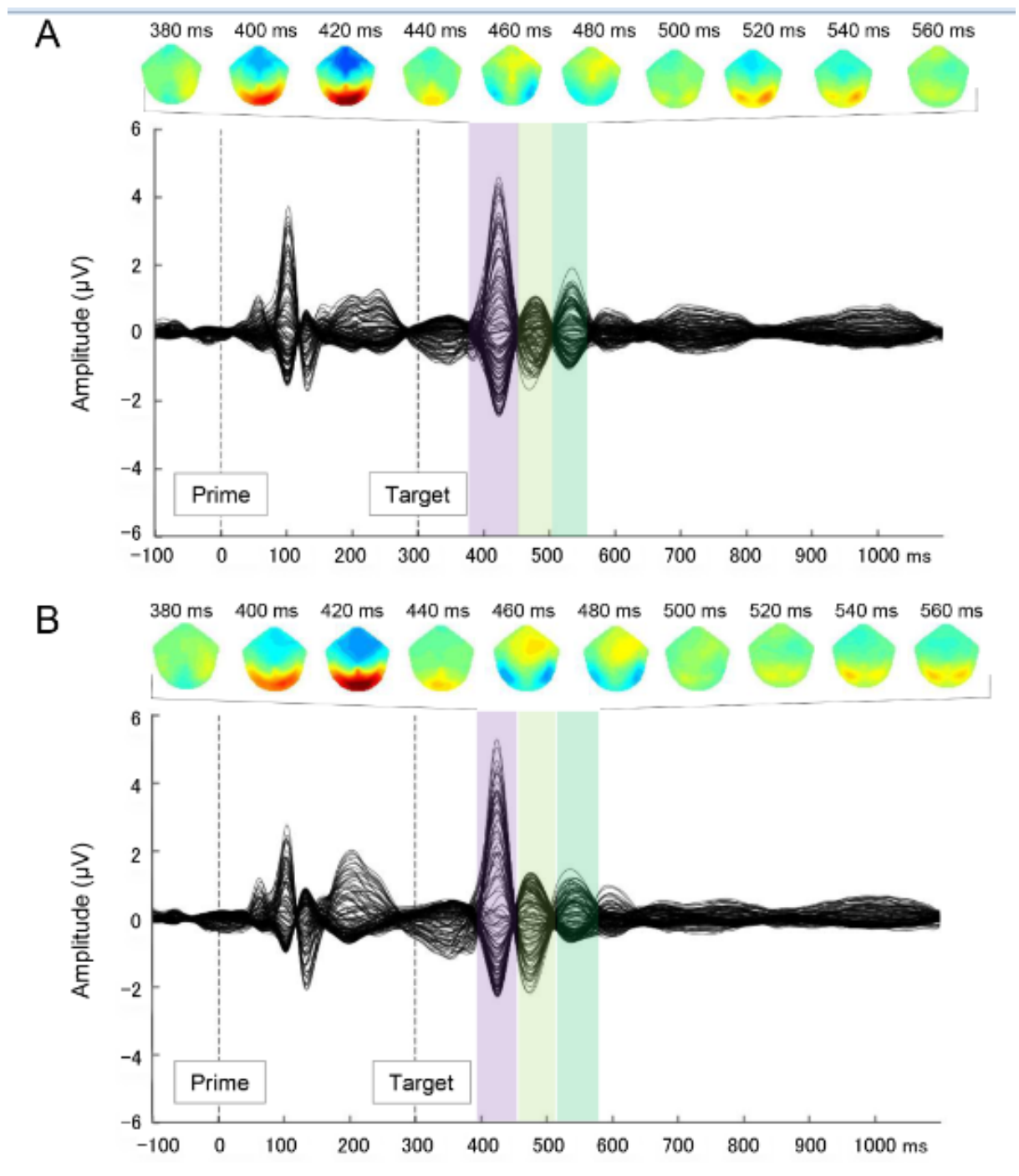

Figure 2

Group-averaged ERPs during the subliminal priming task, with waveforms from the 128 electrodes superimposed. All ERP data for the 6 conditions (female $(A)$ or male $(B) \times 6$ stimuli) were summed and grand-averaged. The ERP responses to the subliminally primed faces and target faces are clearly delineated. Note that three microstates are evident and shaded in purple, light green, and green. These microstates were further analysed. 
A

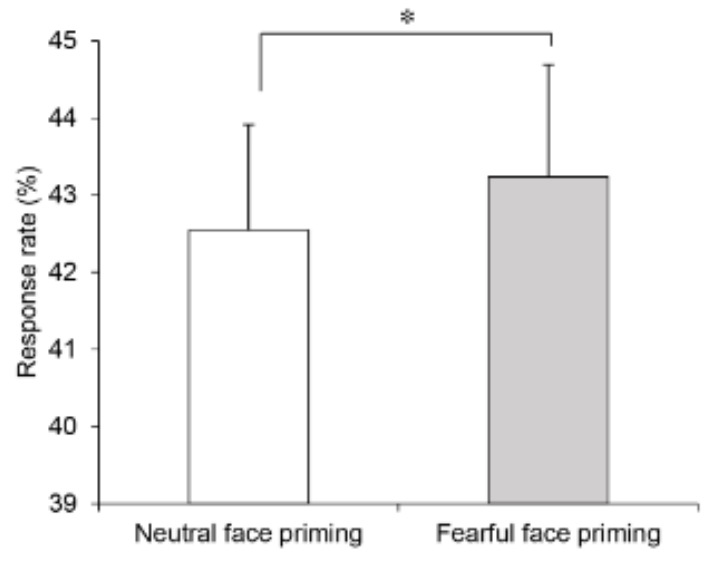

C

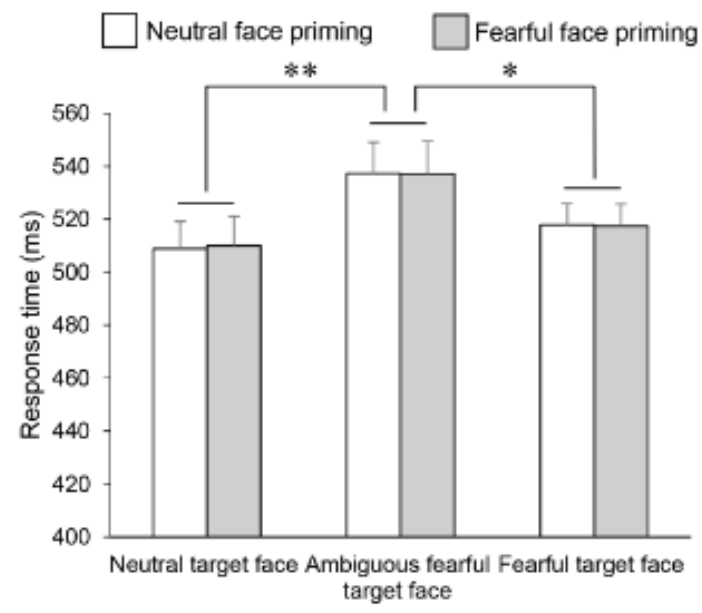

B

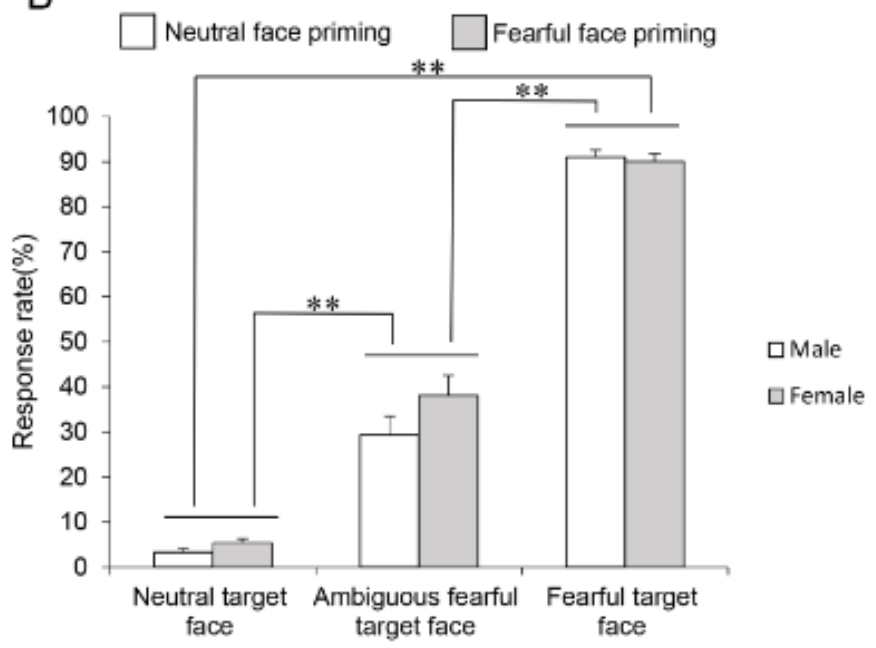

\section{Figure 3}

Microstate analysis outlining periods of topographic differences in the grand mean ERPs for females (A) and males (B). Fearful faces were used as the subliminal prime. Scalp topographies show microstate maps obtained from the crossvalidation procedure. The microstate maps are displayed in sequence of occurrence from left to right. Insets show the different patterns for each condition. Red and blue indicate positive and negative potential values, respectively. The onset of microstate 6 (MS6) for the ambiguous-fearful target face, which corresponded to the N170 time window in females, was later than MS3 and MS4, which corresponded to N170 in males. 
A

Neutral target face

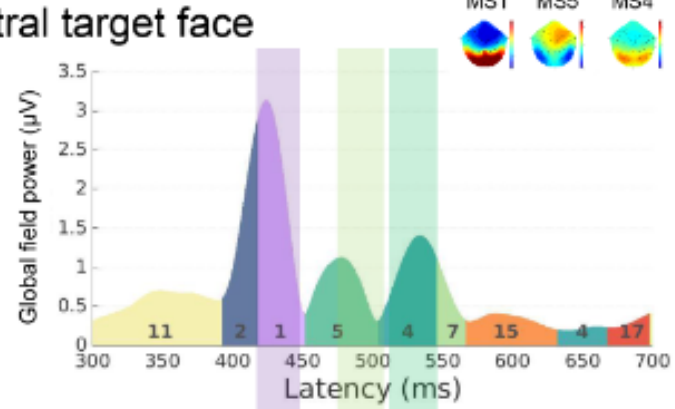

Ambiguous fearful target

face

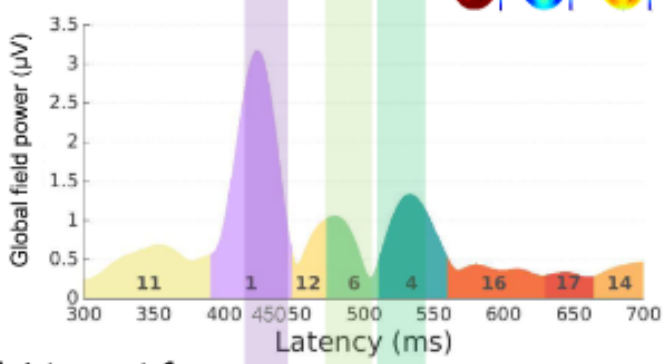

\section{Fearful target face}

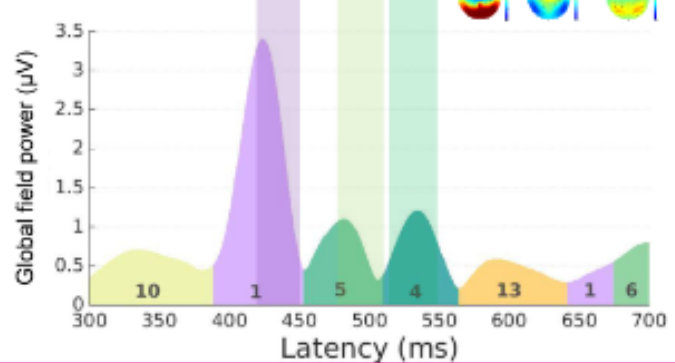

$\mathrm{B}$

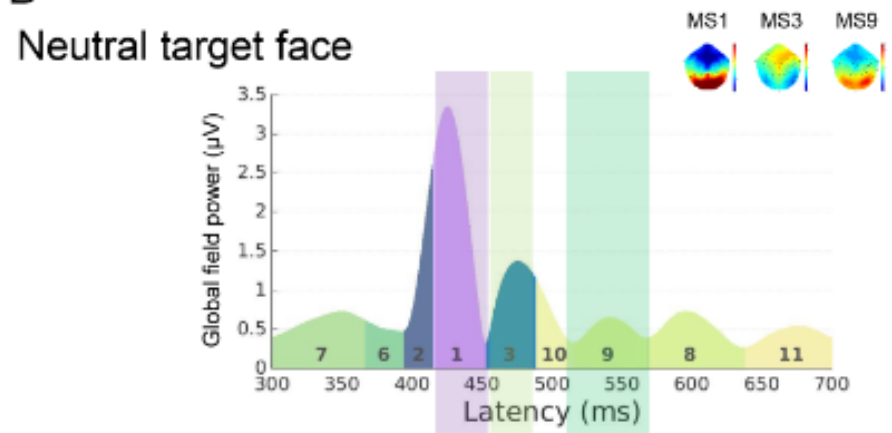

Ambiguous fearful target face

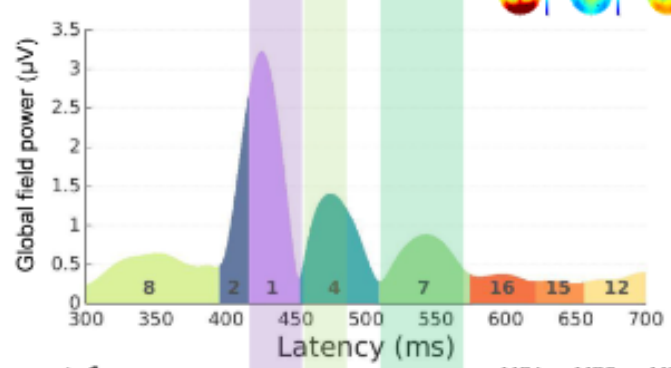

Fearful target face

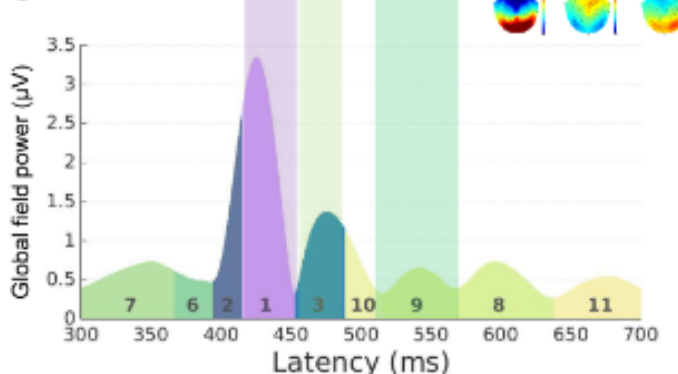

Figure 4

Grand averaged waveforms for the N170 in the right ROI of male and female participants and their scalp topographies. N170 amplitudes in female participants differed from those in males for both primed conditions (A, B) as did the scalp topography (C, D). In female participants, N170 amplitudes for the fearful prime condition were slightly larger than those for the neutral prime condition. For graphical presentation, ERP waveforms are shown $300 \mathrm{~ms}$ after the prime-stimuli onsets. The y-axis ranges from -2.3 to $3.7 \square \mathrm{V}$ for better viewing of the N170 waveforms. 
A Grand averaged ERPs to fearful target face

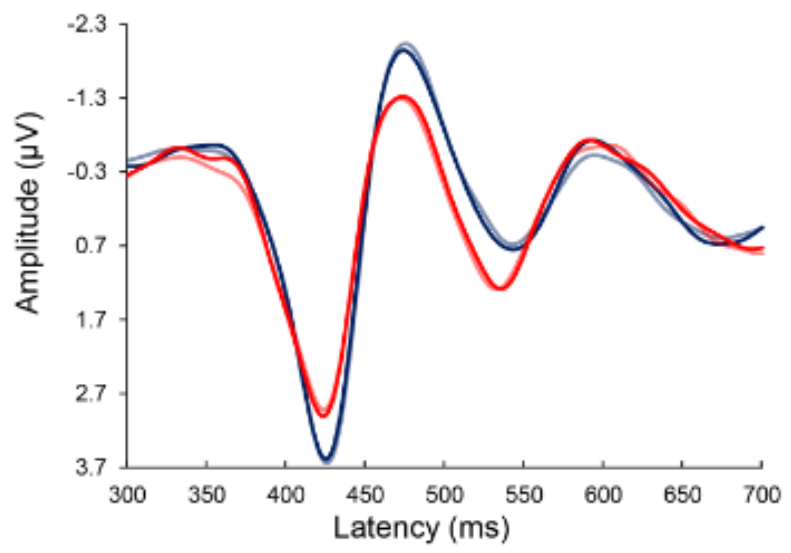

B Grand averaged ERPs to neutral target face

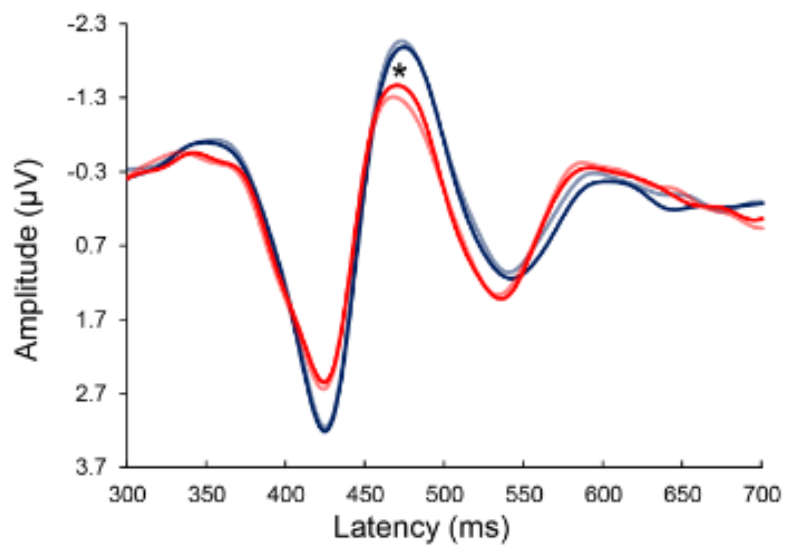

Blue line: Male, Red line: Female

Fearful face priming: dark color, Neutral face priming: light color
C Scalp topography of fearful target face

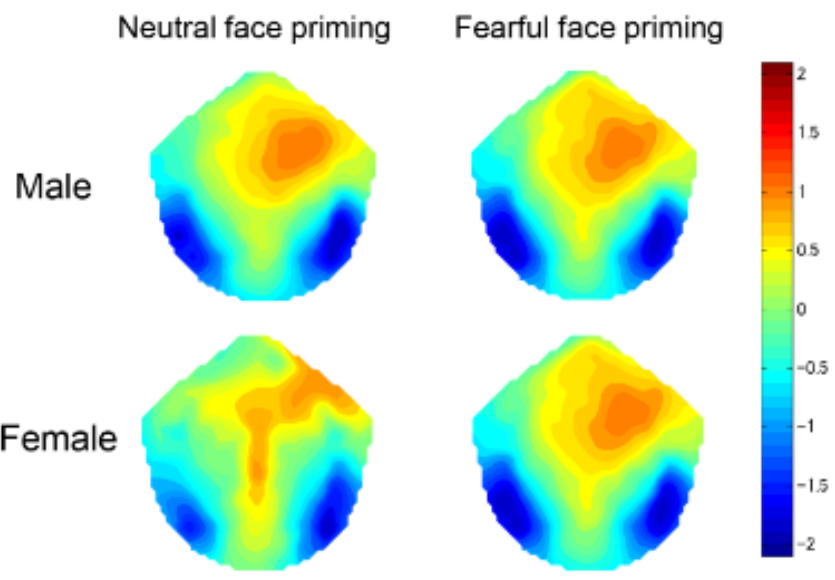

D Scalp topography of neutral target face

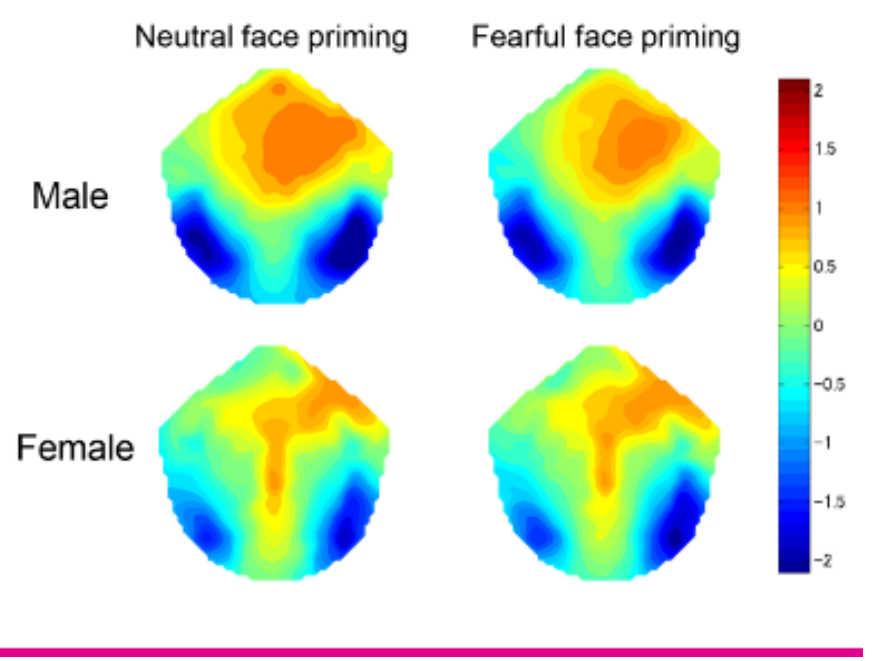

\section{Figure 5}

N170 amplitudes in the right ROIs of male participants were significantly larger in the fearful face-prime condition than in the neutral face-prime condition for target faces primed by fearful face stimuli (A). N170 amplitudes in the right ROIs of female participants were significantly larger for neutral target faces in the fearful prime-face condition than for neutral targets in the neutral prime-face condition (B). 
A

B

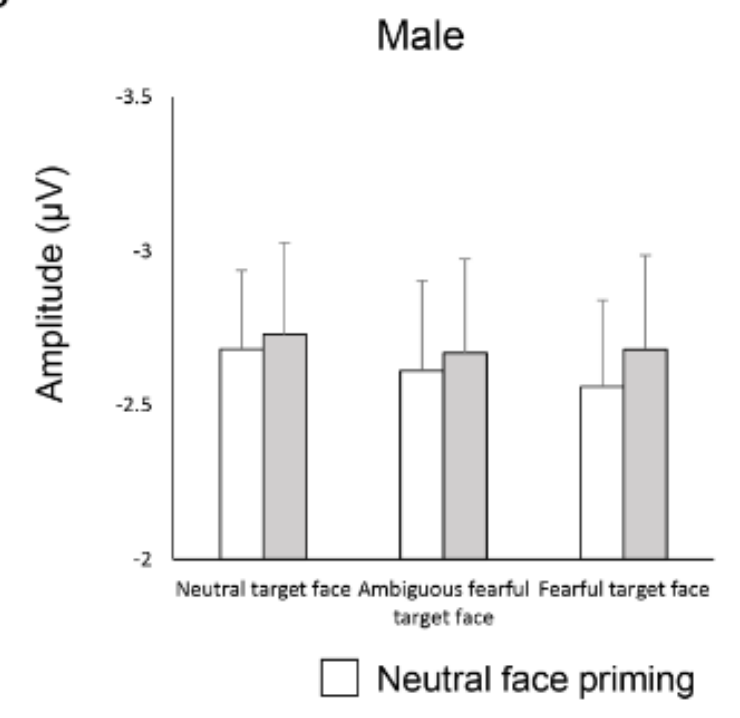

Male
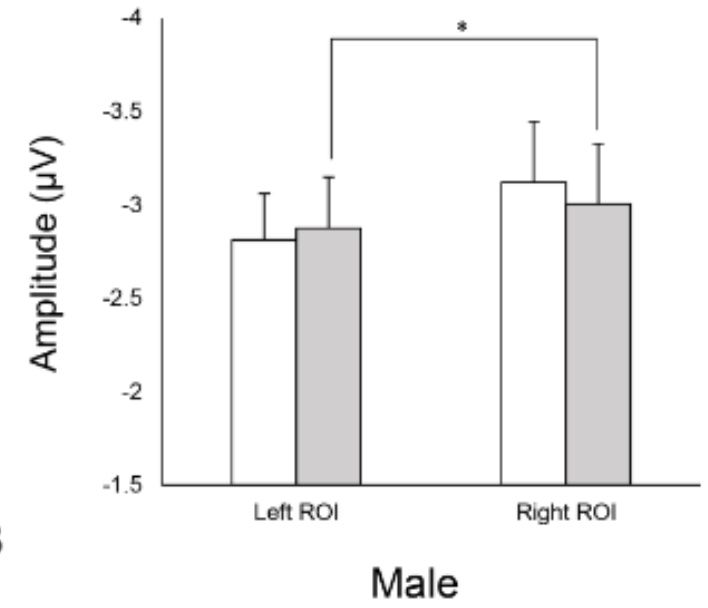

Female

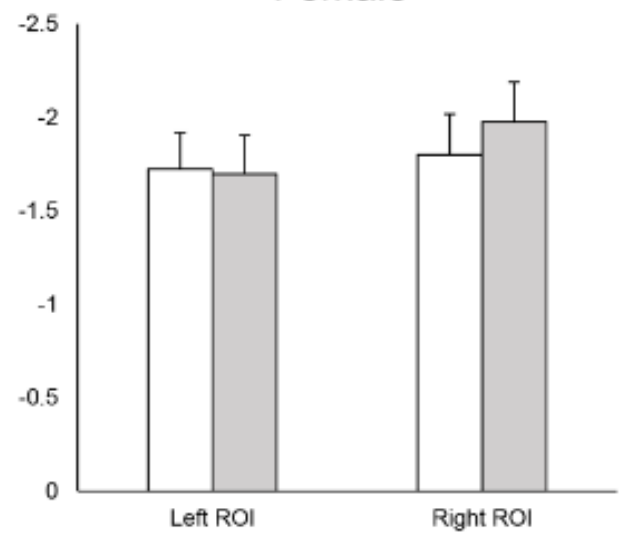

Female

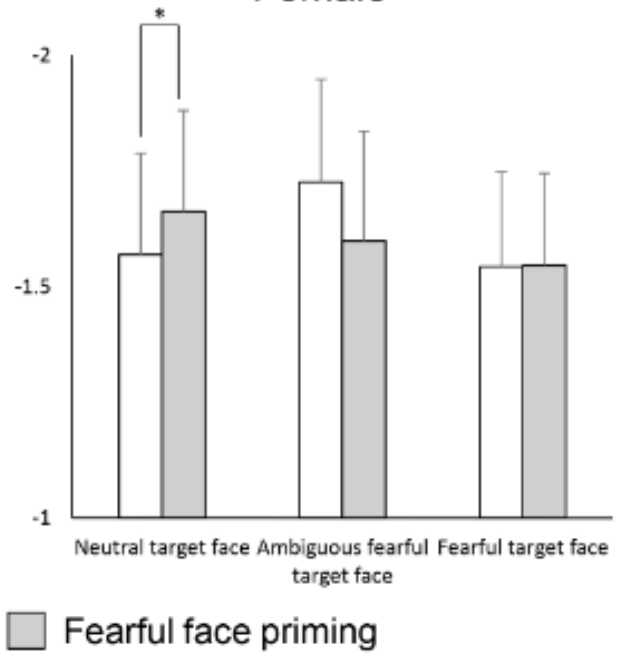

Figure 6

(A) Examples of the face stimuli used in the current experiment. Ambiguous fearful face stimuli were created by morphing neutral and fearful faces together, while keeping the same identity. Three types of $25 \%$ step-morphed faces were used to define emotionally ambiguous fearful faces for each participant. (B) The experimental procedures. Each trial began with mask stimuli and a red fixation cross lasting for $1000 \mathrm{~ms}$. A prime-face stimulus (neutral or fearful) was presented for 17 $\mathrm{ms}$ and immediately followed by the mask stimulus for $283 \mathrm{~ms}$ (SOA was $300 \mathrm{~ms}$ ). A target face stimulus (neutral, ambiguous-fearful, or fearful) then appeared for $800 \mathrm{~ms}$. Participants were instructed to judge whether the target face was fearful or neutral as quickly as possible by pressing the left or right mouse button

\section{Supplementary Files}

This is a list of supplementary files associated with this preprint. Click to download.

- Additionalfile1.pdf 